\title{
Some Issues of Controlling Mass Transfer in a Coal Array with Low-pressure Watering
}

\author{
Ivan Elkin \\ Department of Physics \\ T. F. Gorbachev Kuzbass State \\ Technical University \\ Kemerovo, Russia \\ jelkin@mail.ru
}

\begin{abstract}
The results of researches of mass transfer in a coal array and its conditions are described in the article. The influence of various physical processes on mass transfer is considered. An essential factor determining the direction of mass transfer in the coal array is the distribution of capillaries by classes. The physical effect for controlling mass transfer is directed at changing the structure of the capillary-porous space of coal. On the other hand, controlling of mass transfer is possible when the fluid properties change: contact angle of watering, coefficient of viscosity, coefficient of surface tension.
\end{abstract}

Keywords--coal, coal seam, filtration, watering, contact angle of watering, surfactants, permeability, coefficient of permeability

\section{INTRODUCTION}

Preliminary low-pressure watering of coal array is one of the main measures for the prevention of gas dynamic phenomena, increased dust formation, dust emission during coal-face and preparatory working. Preliminary watering using surface-active substances allows: to reduce gas emission in mine workings by 65 to $75 \%$, dustiness of the atmosphere to $80 \%$; reduce the gas-dynamic activity of the seam; to align the strength parameters of the stratum along the strike and composing strata [1-4]. In the process of filtration and watering by surface-active substances, the physic-mechanical properties of the coal array change, which has a significant effect on the safety of mining operations on coal seams dangerous for sudden outbursts, crush bursts, etc. [5], [6], [7].

The main task in the application of technology is the maximum saturation of coal with water. The solution of safety problem during mining operations is aimed at increasing the wettability, increasing the penetrating power of the liquid, and distributing the liquid in the array evenly.

One of the actual safety problems during mining operations with the use of surface-active substances is the development of a surfactant that allows solving the technological problems with greater efficiency. In connection with this, a detailed study of the interfacial interactions at the coal-liquid-gas boundary is relevant.

In practice, for calculating the technological parameters of preliminary watering of coal seams, engineers are guided by the technical capabilities and instructions for conducting mining operations on coal seams disposed to crush burst and emissions [1]. The proposed formula for calculating the radius of watering is:

$$
R_{w}=31,6(Q t / \pi h N \gamma)^{0,5},
$$

where $N=10\left(W_{\max }-W\right)$ - humidification rate, $1 / \mathrm{t} ; W_{\max }-$ maximum hygroscopic humidity, $\% ; W-$ natural humidity, $\%$; $Q$ - rate of discharge, $\mathrm{m}^{3} / \mathrm{h} ; t$ - time of injection, $h$ - thickness of the reservoir, $\mathrm{m} ; \gamma-$ volumetric density of coal, $\mathrm{t} / \mathrm{m}^{3} ; \pi=3,14$.

As studies show the calculations by formula (1) only approximately estimate the value of the watering radius. Therefore, in order to increase the efficiency of watering and its control, it is necessary to conduct deeper studies of mass transfer processes in the coal array while watering it, to develop a model that allows calculating the main technological parameters of watering: injection pressure, spacing between wells, injection time and etc.

\section{MATERIALS AND METHODS OF RESEARCH}

For the purpose of experimental researches, coals of various grades, varying degrees of metamorphism, physicochemical properties, different moisture and structural features, porosity, strength characteristics, as well as distilled water and solutions of various surfactants were used. "Neolas", "Elfor", etc. were used as the surface-active substances as the most common in the mining industry.

As it is well-known one of the main indicators of interfacial interactions at the interface between the coalsolution surfactant-gas or the solid body-solution surfactantair is the contact angle of watering. The contact angle of watering is the most informative characteristic of interfacial interactions. The choice of this parameter as the main for research is influenced by the following factors [7]:

1) the structure of the studied solid: porosity, in homogeneity of coal;

2) physical-and-chemical properties of the studied liquid;

3) the goals and tasks of the studied technological process.

By studying the change in contact angle of watering, the possible conditions for effective control of mass transfer in the coal array are determined [8-15]. 
Considering that coal is a structurally complex capillaryporous solid body that has heterogeneity in structure, as well as in chemical composition and properties. In this sense, this is why complex generalized macroscopic characteristics will more accurately characterize the main properties of this research object in interactions with other substances, surfactant solution, with gas $[16,17]$.

The coal array is a body with a non-uniform capillaryporous structure saturated with a gas hydrate mixture, which is under dynamically changing conditions during mining operations. The change in external conditions will determine the nature and direction of the flow of complex gas-dynamic processes in the array, the result of mass transfer of fluid and gas. In these conditions, it is necessary to correctly predict and implement controlled low-pressure watering of the coal array. The main task is to control and forecast the mass transfer.

In describing the motion of a liquid and gas in a coal array, during watering, the differential equations of mass transfer are used. For a two-phase system, they will look like:

1) for gas

$$
m \frac{\partial}{\partial t}\left(v \rho_{g}\right)=-\operatorname{div}\left(\rho_{g} \vec{v}_{g}\right)+I_{g} ;
$$

2) for the liquid phase

$$
m \frac{\partial}{\partial t}\left(s \rho_{w}\right)=-\operatorname{div}\left(\rho_{w} \vec{v}_{w}\right)+I_{w},
$$

where $v, s$ - volumetric gas and water saturation; $I_{g}, I_{w}-$ source of liquid or gas or drain; $\rho_{\mathrm{g}}, \rho_{\mathrm{w}}$ - density of gas and liquid; $v_{g}, v_{w}$ - gas speed, fluid speed, respectively; $m-$ porosity.

The mass transfer equation has a simple analytical solution for isotropic dispersion media. The solution of the problem of liquid filtration in a gas saturated solid is complicated if the filtration proceeds in a solid having a polycarpellary structure. In this case, the pore size distribution for natural conditions is an uneven distribution, depending on the initial mining and geological conditions of coal formation and dynamic processes in the array due to technological works. The distribution of pores along the radii in the array creates an additional heterogeneity in the filtration.

At a high fluid velocity, in the first approximation, the kinetic processes at the gas-coal interface are not taken into account, i.e. there are no processes of sorption and desorption, there is no hysteresis of gas adsorption on the coal surface [7].

To solve the boundary value problem, the boundary and initial conditions for the pressure are added to the system of equations.

In the non-stationary flow of the watering process, many coefficients in equations (2) - (3) vary depending on external conditions, impacts or other factors. These relationships can be represented as a set of empirical functions, following from field observations.

\section{RESULTS}

We have developed a program that allows calculating the above-mentioned mass transfer equations for the main technological parameters of watering a coal mass on the basis of numerical methods for solving differential equations, obtaining general filtering relationships for homogeneous and inhomogeneous arrays. The main technological characteristics in the calculations are: the time of watering the gas-saturated coal mass for a given radius of humidification, the necessary humidity, the flow rate of the liquid, porosity, etc.

On the basis of calculations it is shown that for a homogeneous part of the array, the surface of the watering zone will take the form of an ellipsoid. The developed program allows determining the effective watering radius. The results of the calculation are in good agreement with the results of fluid injection in full-scale conditions [1-4].

It is shown that the pressure of the liquid in the array as it moves away from the well gradually increases with time and asymptotically approaches a certain limiting value $p_{\max }$.

The results of the calculation show that the humidity in the array is distributed unevenly during the watering even with a homogeneous isotropic structure. There are zones of sharp heterogeneity in the degree of watering. Figure 1 shows the results of calculating the humidity distribution in the array for different points relative to the location of the well at different times.

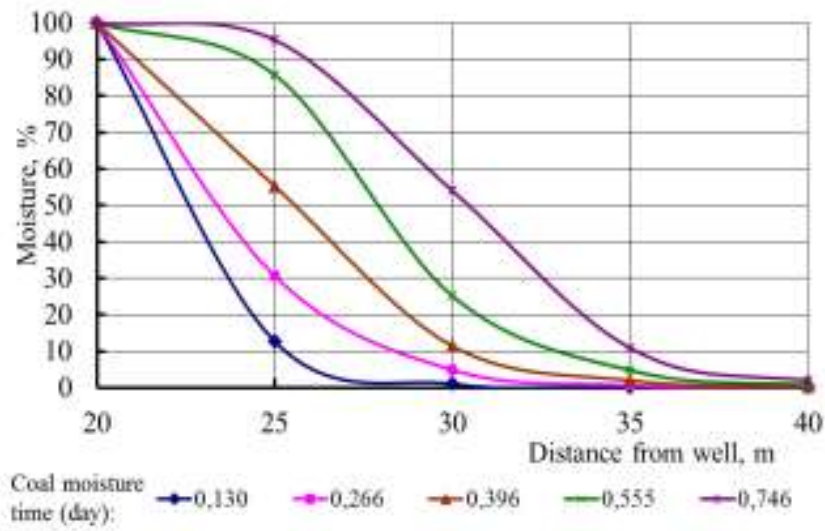

Fig. 1. Distribution of watering in the array after humidification at different times of injection

With high heterogeneity of the array, as calculations show, the outer surface (front) of the watering zone is strongly deformed in inhomogeneous areas. Areas with low permeability appear inside the watering zones. The liquid, circling the zones with low permeability, penetrates these zones. Determining the necessary pressure and time of humidification, the optimal arrangement of the wells in relation to cracks, faults and other inhomogeneity, it is possible to achieve complete qualitative hydration of the array in zones with low permeability. Model calculations show that areas with increased permeability, where macrocapillary systems are located, cracks, faults of geological and geological origin, have a negative effect on the homogeneity of the watering process. The liquid is filtered through such zones over long distances from the well, without affecting the areas with low permeability adjacent to them, the quality of watering decreases. In this case, the location of the wells for watering the coal seam is important. 
It should be such that the wells do not intersect the zones with high permeability.

\section{DISCUSSION}

To research the issue of mass transfer under physical conditions, the influence of dynamically changing conditions on the watering process, it is necessary to research the micro-capillary structure of coal. In this case, we are interested in the capillary-porous structure of coals and its features, depending on the coal grades, stress condition in the edge of the coal array and in the zone of faults. The study of the coal structural characteristics has been carried out by many researchers, and it is the central area of petrography research. A feature of the coal structure presupposes capillary distribution in all classes, respectively, in size. An analysis of experimental studies of the microcapillary structure shows that for a poly-capillary solid (unbroken coal) the pore distribution along the radii and the number of capillaries is related between each other by a normal discrete ratio.

$$
N_{i}=\alpha R_{i}^{-\beta},
$$

where $\alpha, \beta$ - constant for a given grade of coal; $N_{i}-$ number of capillaries in the $i$-th class; $R_{i}$ - average radius of the capillary in the $i$-th class.

Generally, the total number of capillaries is defined by the formula

$$
N=\sum_{i=1}^{n} N_{i}
$$

or

$$
X=\int_{S_{\mathrm{r} s}}^{\mu_{2 \mathrm{~L}}} f(R) d R
$$

where $\mathrm{f}(R)$ - nonlinear function of capillary distribution along radii; $n$ - number of classes.

The total number of classes $n$ depends on the conditions of the given task and the accuracy of its solution and can take from 5 to $\infty$. In our model calculations, this value assumed equal 34 as the optimal value for the calculations.

The constants $\alpha, \beta$ are found from the normalization conditions:

$$
\begin{aligned}
& V_{u}=\sum_{i=1}^{n} \pi R_{i}^{2} N_{i} l_{i}, \\
& S_{u}=\sum_{i=1}^{n} 2 \pi R_{i} N_{i} l_{i},
\end{aligned}
$$

where $V_{u}, S_{u}$ - specific volume and specific surface of pores found experimentally by adsorption methods; $l_{i}-$ length of the capillary.

Some calculated values for the developed program are given in Table I.

Figure 2 shows the results of calculations of the relations between the radii of capillaries and the number of capillaries in the class for coals with different physical-and-mechanical structures, with different structures and the ability to gas dynamic activity. The distribution of capillaries along radii is conveniently represented in logarithmic coordinates.

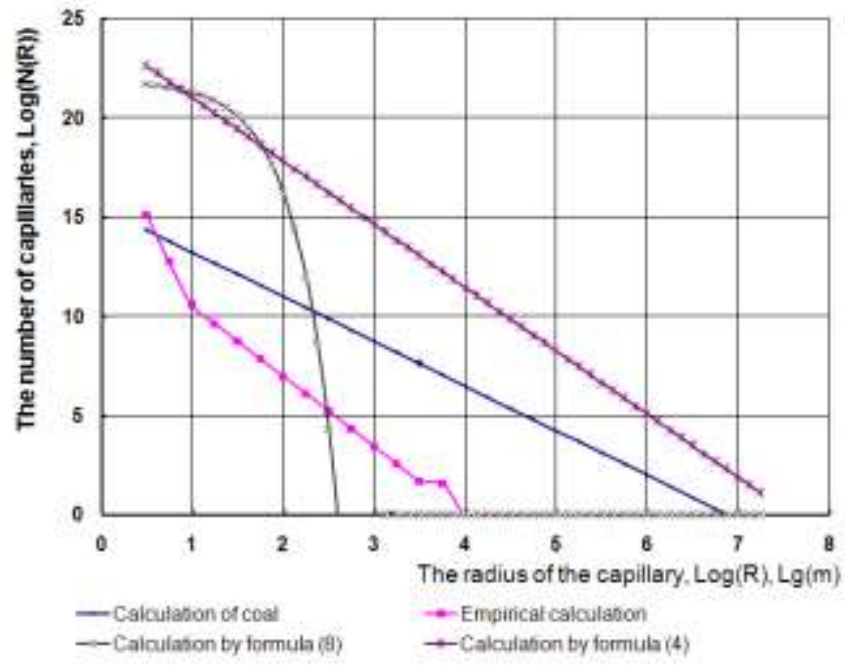

Fig. 2. Capillaries class distribution

Note that the distribution function is written in the form

$$
N_{i}=\alpha e^{\beta / R},
$$

According to the research, a characteristic parameter that exerts on mass transfer in a coal array is fracturing, which is represented as a set of cracks in a rock array of non-tectonic and tectonic origin with high fluid conductivity. The presence of cracks perpendicular to tectonic origin, directed perpendicular to the bedding in the coal array, significantly affects the hydrodynamics. A certain number of cracks is positive for watering.

TABLE I. THE RESULTS OF THE CALCULATION OF THE CONSTANT A AND B AND FOR THE COALS OF DIFFERENT METAMORPHIC GRADE

\begin{tabular}{|c|c|c|c|c|c|}
\hline $\begin{array}{c}\text { Volatile } \\
\text { output } \\
\text { coal, } \%\end{array}$ & $\begin{array}{c}\text { Specific } \\
\text { area, } \mathrm{m}^{2} / \mathrm{g} \\
\text { adsorption } \\
\mathrm{CH}_{3} \mathrm{OH}\end{array}$ & $\begin{array}{c}\text { Specific } \\
\text { volume, } \mathrm{sm}^{3} / \mathrm{g} \\
\text { adsorption } \\
\mathrm{CH}_{3} \mathrm{OH}\end{array}$ & $\begin{array}{c}\text { Polarity, } \\
\text { conv. } \\
\text { units }\end{array}$ & $\alpha$ & $\beta$ \\
\hline 43,2 & 205 & 0,127 & 1,07 & $6,750 \mathrm{E}-09$ & 3,281 \\
\hline 41,3 & 147 & 0,124 & 1,03 & $3,990 \mathrm{E}-08$ & 3,182 \\
\hline 40,6 & 127 & 0,12 & 1,1 & $6,370 \mathrm{E}-08$ & 3,153 \\
\hline 29 & 73 & 0,076 & 0,75 & $5,899 \mathrm{E}-08$ & 3,13 \\
\hline 23,4 & 92 & 0,067 & 0,61 & $1,006 \mathrm{E}-08$ & 3,225 \\
\hline 22,1 & 84 & 0,061 & 0,45 & $9,012 \mathrm{E}-09$ & 3,226 \\
\hline 21,4 & 86 & 0,061 & 0,5 & $7,858 \mathrm{E}-09$ & 3,233 \\
\hline 18,5 & 98 & 0,066 & 0,4 & $6,184 \mathrm{E}-09$ & 3,251 \\
\hline 16,4 & 111 & 0,083 & 0,47 & $1,445 \mathrm{E}-08$ & 3,217 \\
\hline 13,3 & 117 & 0,096 & 0,27 & $2,705 \mathrm{E}-08$ & 3,19 \\
\hline
\end{tabular}

As the practice showed, at a certain concentration of cracks degassing of the coal seam has maximum efficiency. In this case, increasing the fracture by an artificial method can lead to the opposite effect, to a decrease in the degassing efficiency. 
The results of the research show that the structure of coal and the chemical composition of the coal substance help to determine which of the methods of direct impact and activation of mass transfer are more acceptable, and will have the greatest effect.

The application of physical and chemical methods of influence is aimed at changing the properties of the array. The aim of the impact is to change the distribution of capillaries by class. On the other hand, the change in fluid properties leads to a corresponding change in the dynamics of mass transfer.

\section{CONCLUSIONS}

Based on the calculations we can conclude that at a certain permeability of the coal and including additional one created by the artificial cracks, there are certain optimal parameters for the degassing of coal. Similar optimal parameters are the same for hydrodynamic watering of the coal array.

The presence of fractures leads to a strong heterogeneity, which complicates the use of classical analytical methods. Numerical methods for solving the equation of mass transfer allow us establishing the distribution of liquid in an inhomogeneous coal array, taking into account its structural features, the presence of solidness in the array, faults, and stress condition in the edge of the coal array. In practical terms, this is facilitated by the use of programs for the calculation of technological parameters [19], [20].

According to the results of researches it is shown, that the maximum effective watering is reached if the distribution of capillaries corresponds to the normal law, the normal function in the form of equation (4). The transition from one class to another will not experience jumps in the number of capillaries in the class.

The obtained results can be used in the design of technologies for dust control in preliminary workings, preliminary watering of the coal seam used to control the state of the coal array by applying surfactant solutions. All that will improve the safety of mining operations and increase the safety of coal seams mining using high-tech complexes when developing coal deposits by underground method.

\section{REFERENCES}

[1] O. I. Chernov, and V. Y. Al'perovich, Principles of integrated methods to fight coal dust, gassing, sudden coal and gas, rock burst and endogenous fires in coal mines, Kemerovo: Book Publishers, p. 70,1961

[2] O. I. Chernov, and E. S. Rozantsev, Preparation of mine fields with gassing and sudden outburst layers, Moscow: Nedra, p. 287, 1975.

[3] V. V. Dyirdin, and A. I. Shikanov. Evaluation of shock and wetlands outburst coal seams, Kemerovo: Kuzbassvuzizdat, p. 134, 2000.
[4] E. A. Plotnikov, et al. Prevention and dynamic gas-dynamic phenomena in underground coal seams, Kemerovo: Kuzbassvuzizdat, p. $165,2010$.

[5] Y. F. Vasyuchkov, Physical and chemical methods of decontamination of coal layers, Moscow: Nedra, p. 254, 1986.

[6] B. M. Ivanov, and G. N. Faith, Mechanical and physico-chemical properties of coal seams outburst, Moscow: Nauka, p. 194, 1979.

[7] I. S. Elkin, Interfacial interaction when wet coal seams, Saarbrucken: LAP, p. 119, 2014.

[8] B. D. Summ, Foundations of Colloid Chemistry, Moscow: Academy, p. $240,2007$.

[9] A method of selecting surfactants in wetting coals permeability coefficient. The patent for the invention № 2533562. Patent: VPO "KuzGTU T.F. Gorbachev"(KuzGTU) (RU) - Application № 2012145884. Priority of invention of 07.16.2013 Registered in the State Register of Inventions of the Russian Federation of 22.09, 2014.

[10] D. A. Trubitsyna, "Rapid method for evaluating the effectiveness of the use of wetting agents to control dust," Bulletin VostNII, vol. 2, pp. 202-206, 2010

[11] G. A.Martynov, et al. "Hysteresis of the edge angle on homogeneous surfaces," Kolloid. zhurn., vol. 39(3), pp. 472-484, 1977.

[12] C. Journet, S. Moulinet, C. Ybert, S. T. Purcell and L. Bocquet, "Contact angle measurements on superhydrophobic carbon nanotube forests: Effect of fluid pressure," Europhysics Letters, vol. 71(1), pp. 104-109, 2005.

[13] J. Drelich, J. S. Laskowski, and M. Pawlik, "Improved Sample Preparation and Surface Analysis Methodology for Contact Angle Measurements on Coal (Heterogeneous) Surfaces," Coal Preparation, vol 21(3), pp. 246-275, 2000.

[14] A. K. Das, P. K. Das, "Equilibrium shape and contact angle of sessile drops of different volumes-Computation by SPH and its further improvement by DI," Chemical Engineering Science, vol. 65(13), pp. 4027-4037, 2010

[15] L. A. Nazarova, L. A. Nazarov, et al. "Determination of diffusion coefficient and gas content in coal on the basis of the inverse problem solution," Physico-technical Problems of Mineral Development, vol. 5, pp. 15-24, 2012.

[16] V. A. Arkhipov, D. Yu. Paleev, Yu. F. Patrakov, A. S. Usanina, "Determination of the edge angle of wetting of a coal surface," Physico-technical Problems of Mineral Development, vol. 5, pp. 23$28,2011$.

[17] V. A. Arkhipov, D. Yu. Paleev, et al. "Determination of the edge angle of wetting of a coal surface," Physico-technical Problems of Mineral Development, vol. 3, pp. 101-102, 2011.

[18] The federal rules and regulations in the field of industrial safety "instructions Anti-dust in coal mines", Moscow: Closed Joint Stock Company "Scientific and Technical Research Center of Industrial Safety", p. 56, 2014

[19] Program of calculation of technological parameters of coal seam moisture, Certificate of state registration of computer program No. 2014614484. Rightholder: VPO "KuzSTU im. T. F. Gorbachev". Application No. 2014611759 from 04.03.2014. Date of state registration In the register of computer programs 25.04.2014.

[20] Program for calculation of technological parameters of coal bed degassing, Certificate of state registration of computer program No. 2014619082. Rightholder: VPO "KuzST im. T. F. Gorbachev". Application No. 2014616560 of 08.07.2014. Date of state registration in the register of computer programs 08.09.2014. 